\title{
EMISSÕES DE GASES DO EFEITO ESTUFA DA QUEIMA DE PELLETS DE MADEIRA
}

\author{
Dorival Pinheiro Garcia ${ }^{1 *}$, José Cláudio Caraschi ${ }^{2}$, Gustavo Ventorim² \\ ${ }^{1 *}$ Universidade Estadual Paulista, Faculdade de Engenharia, Programa de Pós-Graduação em Engenharia Mecânica, Guaratinguetá, São \\ Paulo, Brasil - pelletsdemadeira@gmail.com \\ ${ }^{2}$ Universidade Estadual Paulista , Câmpus Experimental de Itapeva, Curso de Engenharia Industrial Madeireira, Itapeva, São Paulo, Brasil - \\ caraschi@itapeva.unesp.br, ventorim@itapeva.unesp.br
}

Recebido para publicação: 01/03/2017 - Aceito para publicação: 12/07/2017

\begin{abstract}
Resumo
As previsões indicam crescimento do uso da biomassa florestal como recurso energético nos próximos anos, sobretudo depois dos recentes acordos firmados pela Cúpula do Clima em Paris (COP21), que apontam a necessidade de substituir combustíveis fósseis por fontes renováveis e de baixas emissões de gases do efeito estufa (GEE). Há poucos estudos relacionando a combustão dos pellets de madeira com os limites dessas emissões estabelecidos para a biomassa florestal. Este estudo comparou as emissões da combustão dos pellets com os limites máximos estabelecidos na Resolução no 436 do CONAMA. Utilizou-se quatro amostras de pellets de madeira e três biomassas florestais (casca de pinus, cavacos de pinus e serragem de eucalipto). Para a combustão foi utilizado um queimador de biomassa vegetal, com alimentação automática e consumo de $14 \mathrm{~kg}$ por hora. As análises das emissões foram realizadas com o analisador eletroquímico Unigas 3000 MKIII, que determinou a composição química dos gases da combustão. Os resultados mostraram que os pellets de madeira têm baixas emissões de $\mathrm{CO}, \mathrm{NO}_{\mathrm{x}}$ e $\mathrm{SO}_{\mathrm{x}}$. Assim, conclui-se que as biomassas florestais atendem aos limites de emissões gasosas estabelecidos pela legislação vigente, com exceção da serragem de eucalipto e a casca de pinus.
\end{abstract}

Palavras-chave: Biomassa florestal; combustível sólido; cinzas; combustão; COP21.

\begin{abstract}
Emissions of greenhouse effect gases from wood pellets burning. Forecasts indicate the growth in use of forest biomass as the energy resource in the coming years, especially after the recent agreements reached at Paris Climate Summit - COP21, which imply the replacement of fossil fuels for renewable ones, with lowemission Greenhouse Gas - GHG. There are few studies relating the wood pellets combustion with the limits of these emissions established for forest biomass. This study compared the pellet combustion emissions with the maximum limits established in Resolution $n^{\circ} 436$ of the National Council of Environment - CONAMA. Four samples of wood pellets and three forest biomasses (pine bark, pine chip and eucalyptus sawdust) were used. A vegetable biomass burner was used for combustion, with automatic feed and consumption of $14 \mathrm{~kg}$ per hour. Emissions analyzes were performed with the Unigas 3000 MKIII electrochemical analyzer, which determined the chemical composition of the combustion gases. The results showed that the wood pellets have low $\mathrm{CO}, \mathrm{NO}_{\mathrm{x}}$ and $\mathrm{SO}_{\mathrm{x}}$ emissions. Thus, it can be concluded that these biomasses meet the gaseous emission limits established by the current legislation, except for eucalyptus sawdust and pine bark biomass.

Keywords: Forest biomass; solid fuel; ashes; combustion; COP21.
\end{abstract}

\section{INTRODUÇÃO}

As emissões de dióxido de carbono $\left(\mathrm{CO}_{2}\right)$, da queima de combustíveis fósseis, contribuiu com cerca de $78 \%$ do aumento dos gases do efeito estufa (GEE) no período de 1970 a 2010. Apesar de um número crescente de políticas de mitigação das mudanças climáticas, essas emissões cresceram 2,2\% ao ano, entre 2000 e 2010. Nos trinta anos anteriores a este período, a velocidade era de 1,3\% ao ano. Por isso, se nada for feito e continuar apenas com as políticas climáticas já existentes, a previsão é que haverá um aquecimento no planeta de $3,7^{\circ} \mathrm{C}$ a $4,8^{\circ} \mathrm{C}$ até o ano de 2100, de acordo com o IPCC - Intergovernmental Panel on Climate Change (2014).

Nesse sentido, a biomassa florestal é uma abundante fonte de energia renovável. Sua utilização na forma de biocombustíveis sólidos, como os pellets de madeira (wood pellets), vem se tornando comum para a produção de energia térmica em países que precisam diminuir suas emissões poluentes. Além disso, os pellets apresentam boas características energéticas como a homogeneidade de formas, elevado poder calorífico e alta densidade energética, que melhoram a eficiência do queimador e facilita a sua operação automatizada (GARCIA-MARAVER et al., 2014; GARCIA et al., 2016a). 
Durante os últimos cinco anos, esse biocombustível sólido se transformou em um importante recurso energético mundial, especialmente na Europa, onde seu mercado é estável e está passando por rápido desenvolvimento (GARCIA et al., 2016a). Os números do consumo de pellets revelam que cerca de 9,2 milhões de toneladas foram consumidos pelos europeus em 2009, 14,4 milhões em 2011 e espera-se um consumo de 50,0 milhões de toneladas para 2020 (BISWAS et al., 2011). Para esses autores, os pellets são um dos maiores produtos de biomassa sólida comercializados internacionalmente.

Por ser um combustível renovável e menos poluente que os derivados do petróleo, os pellets têm sido utilizados por países que precisam diminuir suas emissões de GEE para atender aos acordos firmados no Protocolo de Kyoto e ratificados na Conferência do Clima (COP21), que ocorreu na França, em dezembro de 2015 (ADAMS; LINDEGAARD, 2016). A utilização de pellets de madeira traz benefícios ambientais, como a redução das emissões de $\mathrm{CO}, \mathrm{CO}_{2}, \mathrm{SO}_{\mathrm{x}}$ e $\mathrm{NO}_{\mathrm{x}}$ em comparação com os combustíveis fósseis (JOELSSON; GUSTAVSSON, 2010). Ele é considerado $\mathrm{CO}_{2}$ neutro, ou seja, grande parte das emissões são recuperadas no crescimento da árvore, mantendo o equilíbrio dos gases na atmosfera (LIU et al., 2010; GARCIA et al., 2016a).

Porém, recente estudo de Cornwall (2017) questiona essa afirmação argumentando que o rótulo " $\mathrm{CO}_{2}$ neutro" estimula o desmatamento, prejudica a biodiversidade e, considerando o ciclo de vida dos pellets de madeira, aumentam as emissões líquidas. Entretanto, Carrol e Finnan (2013) relataram que substituindo combustível fóssil por biomassa florestal reduz-se a formação de óxidos de enxofre e nitrogênio (que são os precursores da chuva ácida), devido aos baixos teores desses elementos contidos nos materiais lignocelulósicos.

Contudo, a combustão incompleta da biomassa, que pode ocorrer devido à má qualidade da biomassa florestal ou da tecnologia utilizada para sua queima, também é conhecida como fonte de vários poluentes tais como monóxido de carbono, metano, compostos orgânicos voláteis, hidrocarbonetos aromáticos policíclicos e material particulado fino, que produzem efeitos adversos à saúde (CARROLL; FINNAN, 2013). Por isso, estabeleceu-se os padrões de qualidade do ar por meio da Resolução n 436 do Conselho Nacional do Meio Ambiente, o CONAMA (BRASIL, 2011), que define os limites de emissões para poluentes atmosféricos provenientes dos processos de geração de energia térmica a partir da combustão dos derivados da madeira.

Assim, Amaral et al. (2014) destacaram a importância de mais estudos para preencher as lacunas no conhecimento sobre as emissões dos pellets e outras biomassas florestais. Desta forma, o presente trabalho tem como objetivo investigar as emissões gasosas de quatro amostras de pellets de madeira, comparando-os com outras biomassas florestais (serragem de madeira, casca de madeira e cavacos de madeira) e verificar sua conformidade com a referida Resolução do CONAMA.

\section{MATERIAL E MÉTODOS}

Analisou-se quatro procedências de pellets de madeira (PEL1, PEL2, PEL3 e PEL4) além de casca de Pinus spp. (CASC), cavacos de Pinus spp. (CAVA) e serragem de Eucalyptus spp. (SERR) de duas regiões do Brasil: Sul e Sudeste (Figura 1). Os pellets de madeira são produtos comerciais, por isso os nomes das empresas serão preservados para evitar a promoção positiva ou negativa dessas marcas.

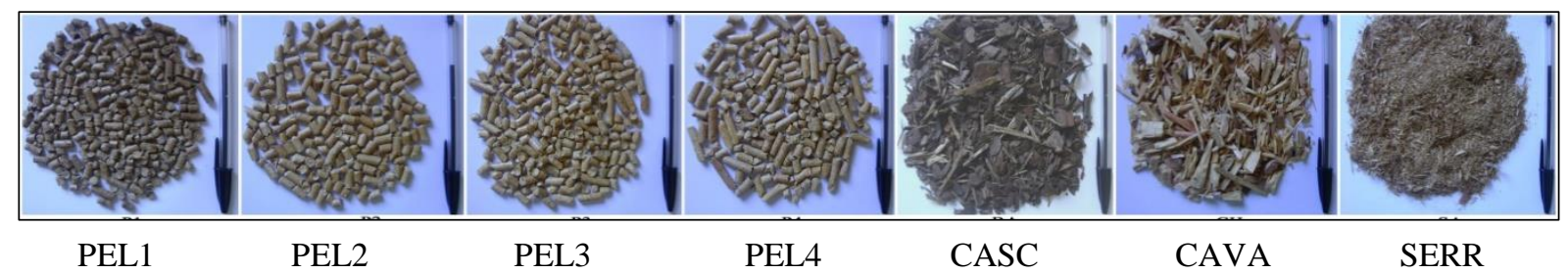

Figura 1. Biomassas vegetais florestais utilizadas para os testes de combustão.

Figure 1. Forest biomass used for combustion tests.

A casca e os cavacos passaram por secagem ao ar livre, em ambiente coberto, alcançando teores de umidade próximos de $15 \%$. As amostras foram armazenadas em local seco e à temperatura ambiente antes da queima e suas caracterizações iniciais estão relacionadas na tabela 1.

Os produtores utilizam os resíduos da indústria madeireira para a produção dos pellets, por isso, não é possível a identificação da espécie florestal porque as matérias-primas são reunidas de várias indústrias madeireiras e serrarias da região.

Efetuaram-se análise química imediata, com as determinações dos teores de umidade (TU), materiais voláteis (MV), cinzas (CZ) e carbono fixo (CF), mediante a metodologia expressa na norma NBR 8112 (ABNT, 
1986), sendo três repetições para cada amostra. Para as análises químicas de lignina, holocelulose e extrativos utilizou-se a norma T211 (TAPPI, 2000).

Determinou-se o poder calorífico superior (PCS) em uma bomba calorimétrica isotérmica marca Ika Works modelo C-5000, por meio da metodologia estabelecida na NBR 8633 (ABNT, 1984) que prescreve o método de determinação do PCS do carvão vegetal a volume constante. Para as biomassas florestais desse estudo, a norma foi adaptada triturando e peneirando os materiais para as análises. Realizou-se três repetições para cada amostra coletada.

Tabela 1. Caracterização inicial das diferentes amostras de biomassa florestal utilizadas na combustão.

Table 1. Initial characterization of the different forest biomass samples used in the combustion.

\begin{tabular}{lllll}
\hline Amostras & Biomassa florestal & Formato & Dimensões & Classificação da biomassa \\
\hline PEL1 & Pellets de madeira & cilíndrica & $6 \mathrm{~mm}$ & Pinus spp. \\
PEL2 & Pellets de madeira & cilíndrica & $6 \mathrm{~mm}$ & Pinus spp. \\
PEL3 & Pellets de madeira & cilíndrica & $6 \mathrm{~mm}$ & Pinus spp. \\
PEL4 & Pellets de madeira & cilíndrica & $6 \mathrm{~mm}$ & Pinus spp. \\
CASC & Casca de pinus & partículas & $>18 \mathrm{~mm}$ & Pinus spp. \\
CAVA & Cavacos de pinus & partículas & $>18 \mathrm{~mm}$ & Pinus spp. \\
SERR & Serragem de eucalipto & partículas & $<3 \mathrm{~mm}$ & Eucalyptus spp. \\
\hline
\end{tabular}

Para o teor de umidade das amostras, depois de peneiradas, elas foram secas em estufa a $103 \pm 2{ }^{\circ} \mathrm{C}$, por 24 horas, seguindo as determinações NBR 14929 (ABNT, 2003).

A densidade a granel (bulk density) foi determinada de acordo com os procedimentos da norma TS 15103 (CEN, 2005) que se aplica aos biocombustíveis sólidos. Para os testes foi utilizado um recipiente cilíndrico de PVC, com volume de 5,0 litros e com relação entre a altura (228 mm) e o diâmetro (167 mm) de aproximadamente 1,37 .

Para a caracterização das cinzas residuais do processo de combustão, cerca de $100,0 \mathrm{~g}$ do material foi coletado e enviado ao laboratório da Indústria Ferro Ligas Maringá, em Itapeva(SP), onde foi analisado com um espectrômetro de fluorescência de raios X, marca Rigaku RIX2000. As análises efetuadas neste equipamento são de detecção dos elementos na forma de óxidos como o $\mathrm{SiO}_{2}, \mathrm{Al}_{2} \mathrm{O}_{3}, \mathrm{Fe}_{2} \mathrm{O}_{3}, \mathrm{MnO}, \mathrm{MgO}, \mathrm{CaO}, \mathrm{Na}_{2} \mathrm{O}, \mathrm{K}_{2} \mathrm{O}, \mathrm{TiO}_{2}$ e $\mathrm{P}_{2} \mathrm{O}_{5}$.

Um analisador portátil marca Unigas 3000 MKIII, fornecido pela Eurotron, foi utilizado para as análises das emissões gasosas e determinação da composição química dos gases da combustão. Este equipamento determina a composição dos gases $\left(\mathrm{O}_{2}, \mathrm{CO}, \mathrm{NO}, \mathrm{NO}_{\mathrm{x}}, \mathrm{SO}_{2}\right)$ pela passagem destes através de um detector eletroquímico.

Os pellets foram alimentados num queimador de biomassa da marca Berneck (Figura 2) através de uma rosca dosadora, com uma taxa de alimentação constante de aproximadamente $14,0 \mathrm{~kg} \cdot \mathrm{h}^{-1}$ de biomassa.

$\mathrm{O}$ ar atmosférico foi fornecido, sem o pré-aquecimento, a uma taxa de fluxo de ar de $40,0 \mathrm{~m}^{3}$. Para que houvesse igualdade de condições na combustão para todas as amostras, padronizou-se os seguintes parâmetros:

- As medições só começavam após 1,0 hora de queima do material, para que houvesse estabilização das chamas, aquecimento por igual das paredes do queimador, aquecimento dos gases da câmara e da chaminé e queima estável das biomassas.

- As duas entradas de ar secundárias do queimador foram mantidas na mesma posição para todas as amostras, para permitir a entrada da mesma quantidade de ar atmosférico na queima.

Com intuito de obter média representativa do fluxo de gás, realizou-se análises a cada minuto de forma a se obter, pelo menos, 105 resultados em duas horas de queima. Ao final da combustão de cada amostra das biomassas florestais, coletou-se cerca de $100,0 \mathrm{~g}$ das cinzas residuais para observação de sua composição química com um analisador eletroquímico.

A análise estatística dos dados originais foi processada no software Excel, buscando avaliar a variabilidade dos dados e o comportamento das variáveis originais com análise descritiva das biomassas florestais, a determinação de parâmetros de tendência central e de dispersão. As biomassas florestais foram caracterizadas por análises físicas, químicas e térmicas com delineamento inteiramente casualizado, com sete tratamentos (tipos de biomassa) e três repetições (por amostra), totalizando 21 unidades amostrais. 


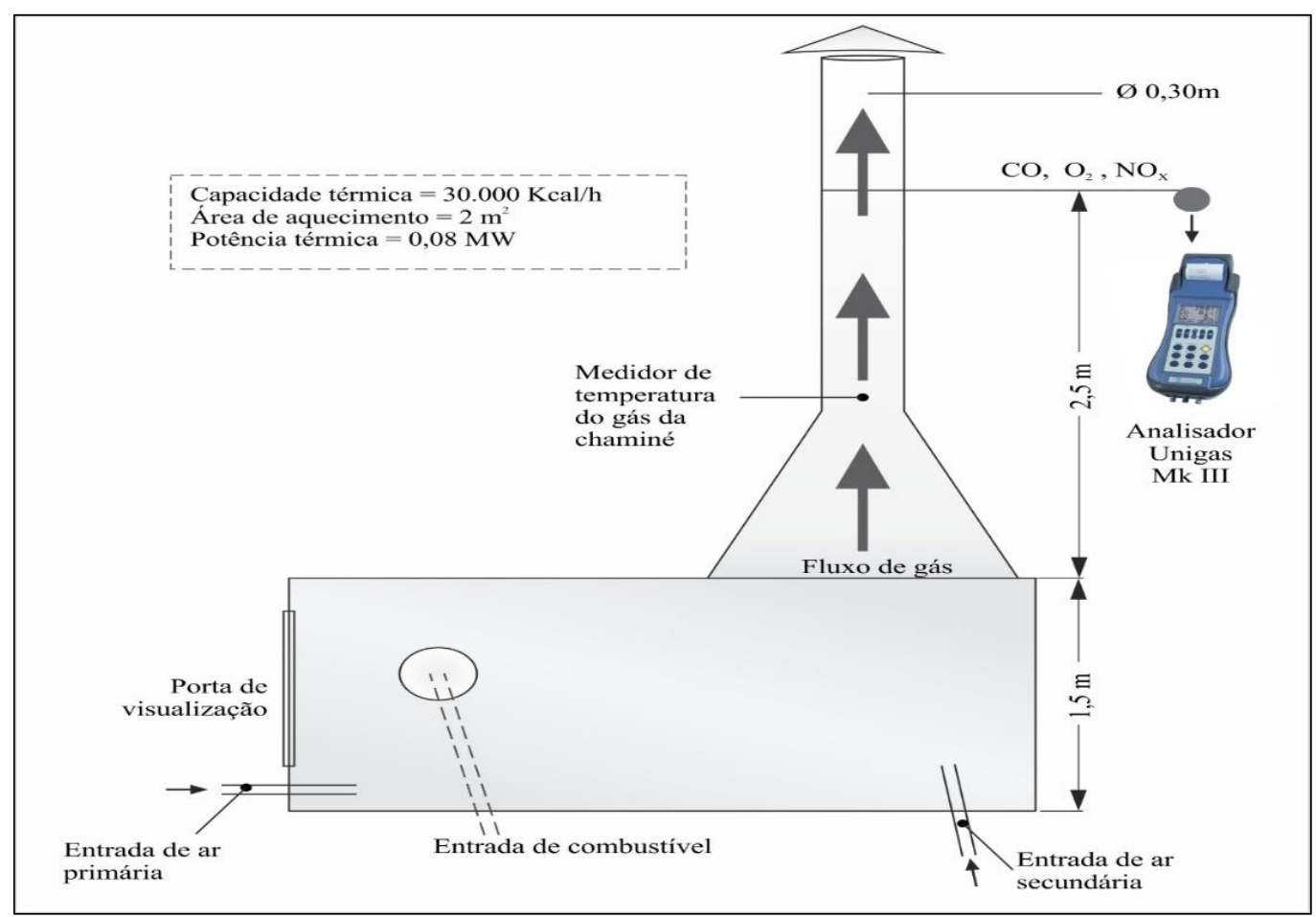

Figura 2. Diagrama do queimador de biomassa florestal utilizado nos testes de combustão.

Figure 2. Diagram of the forest biomass burner used in the combustion tests.

\section{RESULTADOS}

Como se observa na tabela 2, em geral, os valores dos desvios-padrão apresentados revelam que houve baixa variabilidade dos dados.

Tabela 2. Características físicas, químicas e térmicas das biomassas florestais (médias \pm desvio padrão).

Table 2. Physical, chemical and thermal characteristics of forest biomass (mean \pm standard deviation).

\begin{tabular}{lccccccc}
\hline Propriedades & PEL1 & PEL2 & PEL3 & PEL4 & CASC & CAVA & SERR \\
\hline Carbono fixo (\%) & $15,63 \pm$ & $14,70 \pm$ & $15,42 \pm$ & $14,56 \pm$ & $23,94 \pm$ & $17,58 \pm$ & $16,33 \pm$ \\
& 0,27 & 0,12 & 0,87 & 0,46 & 0,25 & 0,37 & 0,42 \\
Materiais voláteis (\%) & $83,40 \pm$ & $84,90 \pm$ & $84,00 \pm$ & $84,90 \pm$ & $74,10 \pm$ & $82,05 \pm$ & $82,45 \pm$ \\
& 0,26 & 0,11 & 0,87 & 0,47 & 051 & 0,46 & 0,52 \\
Teor de cinzas (\%) & $0,93 \pm$ & $0,33 \pm$ & $0,58 \pm$ & $0,54 \pm$ & $3,82 \pm$ & $0,37 \pm$ & $0,65 \pm$ \\
& 0,01 & 0,02 & 0,02 & 0,01 & 0,02 & 0,09 & 0,08 \\
Teor de umidade (\%) & $10,17 \pm$ & $6,76 \pm$ & $7,78 \pm$ & $8,55 \pm$ & $11,22 \pm$ & $10,77 \pm$ & $14,25 \pm$ \\
& 0,06 & 0,21 & 0,07 & 0,09 & 0,35 & 0,12 & 0,15 \\
Extrativos totais (\%) & $3,95 \pm$ & $6,54 \pm$ & $8,38 \pm$ & $5,58 \pm$ & $20,73 \pm$ & $5,61 \pm$ & $6,08 \pm$ \\
& 0,13 & 0,30 & 0,20 & 0,30 & 0,11 & 0,03 & 0,10 \\
Holoceluloses (\%) & $67,25 \pm$ & $65,94 \pm$ & $64,53 \pm$ & $66,03 \pm$ & $35,83 \pm$ & $68,21 \pm$ & $65,10 \pm$ \\
& 0,97 & 0,85 & 0,66 & 0,95 & 0,63 & 0,70 & 0,54 \\
Lignina total (\%) & $29,31 \pm$ & $28,02 \pm$ & $26,79 \pm$ & $28,42 \pm$ & $39,62 \pm$ & $25,81 \pm$ & $28,17 \pm$ \\
Poder Calorífico & 1,05 & 1,08 & 0,57 & 1,15 & 0,96 & 0,80 & 1,02 \\
Superior (MJ.kg ${ }^{-1}$ ) & $18,81 \pm$ & $19,48 \pm$ & $19,13 \pm$ & $18,71 \pm$ & $15,85 \pm$ & $18,43 \pm$ & $18,06 \pm$ \\
Densidade a granel & 0,41 & 0,10 & 0,03 & 0,11 & 0,26 & 0,35 & 0,74 \\
(kg.m ${ }^{-3}$ ) & $647,40 \pm$ & $638,00 \pm$ & $638,17 \pm$ & $640,64 \pm$ & $244,42 \pm$ & $175,50 \pm$ & $210,62 \pm$ \\
& 3,66 & 24,92 & 15,61 & 22,98 & 19,79 & 18,04 & 13,96 \\
\hline
\end{tabular}

Os resultados médios das análises dos gases de combustão são apresentados na tabela 3. Os pellets apresentaram maior temperatura dos gases de combustão na saída da chaminé $\left(160,1-187,3{ }^{\circ} \mathrm{C}\right)$ do que as outras biomassas $\left(132,8-139,3^{\circ} \mathrm{C}\right)$. Isso está associado à baixa umidade dos PEL1, PEL2, PEL3 e PEL4 (6,76-10,17\%) e elevado PCS (18,71-19,48 MJ.kg ${ }^{-1}$ ) desses biocombustíveis sólidos em comparação com as biomassas 
florestais CASC, CAVA e SERR, que possuem umidade entre 10,77-14,25\% e PCS na faixa de 15,85$18,43 \mathrm{MJ} \cdot \mathrm{kg}^{-1}$.

Tabela 3. Resultados médios ( \pm desvio padrão) obtidos nas análises dos principais gases da combustão.

Table 3. Average results ( \pm standard deviation) obtained in the analyzes of the main combustion gases.

\begin{tabular}{cccccc}
\hline $\begin{array}{c}\text { Biomassa } \\
\text { Florestal }\end{array}$ & $\mathbf{O}_{\text {2ref. }}(\boldsymbol{\%})$ & $\mathbf{T}_{\text {gás }}\left({ }^{\circ} \mathbf{C}\right)$ & $\mathbf{O}_{\mathbf{2}}(\boldsymbol{\%})$ & $\mathbf{C O}\left(\mathbf{m g} \cdot \mathbf{m}^{-\mathbf{3}}\right)$ & $\mathbf{N O}_{\mathbf{x}}\left(\mathbf{m g} \cdot \mathbf{m}^{-\mathbf{3}}\right)$ \\
\hline PEL1 & 8,0 & $160,1 \pm 18,1$ & $19,5 \pm 0,3$ & $3.666 \pm 742$ & $212 \pm 30$ \\
PEL2 & 8,0 & $179,9 \pm 26,7$ & $19,3 \pm 0,4$ & $2.822 \pm 612$ & $371 \pm 36$ \\
PEL3 & 8,0 & $187,3 \pm 18,7$ & $19,2 \pm 0,4$ & $4.182 \pm 605$ & $230 \pm 32$ \\
PEL4 & 8,0 & $185,1 \pm 14,7$ & $18,7 \pm 0,4$ & $2.459 \pm 395$ & $184 \pm 29$ \\
CASC & 8,0 & $136,9 \pm 4,7$ & $19,9 \pm 0,1$ & $14.170 \pm 1248$ & $307 \pm 31$ \\
CAVA & 8,0 & $139,3 \pm 5,9$ & $19,7 \pm 0,2$ & $4.188 \pm 357$ & $184 \pm 26$ \\
SERR & 8,0 & $132,8 \pm 7,5$ & $19,9 \pm 0,3$ & $9.425 \pm 860$ & $126 \pm 25$ \\
\hline
\end{tabular}

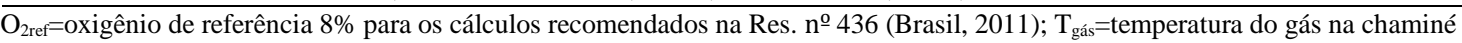

A evolução das emissões de CO na combustão das biomassas florestais estão apresentados na figura 3. O limite estabelecido pelo CONAMA serviu como parâmetro de cálculo dos teores de $\mathrm{CO}$ e $\mathrm{NO}_{\mathrm{x}}$. A linha pontilhada vermelha representa o limite máximo para as emissões de monóxido de carbono, de $7.800 \mathrm{mg} \cdot \mathrm{m}^{-3}$, para os combustíveis de biomassas florestais.

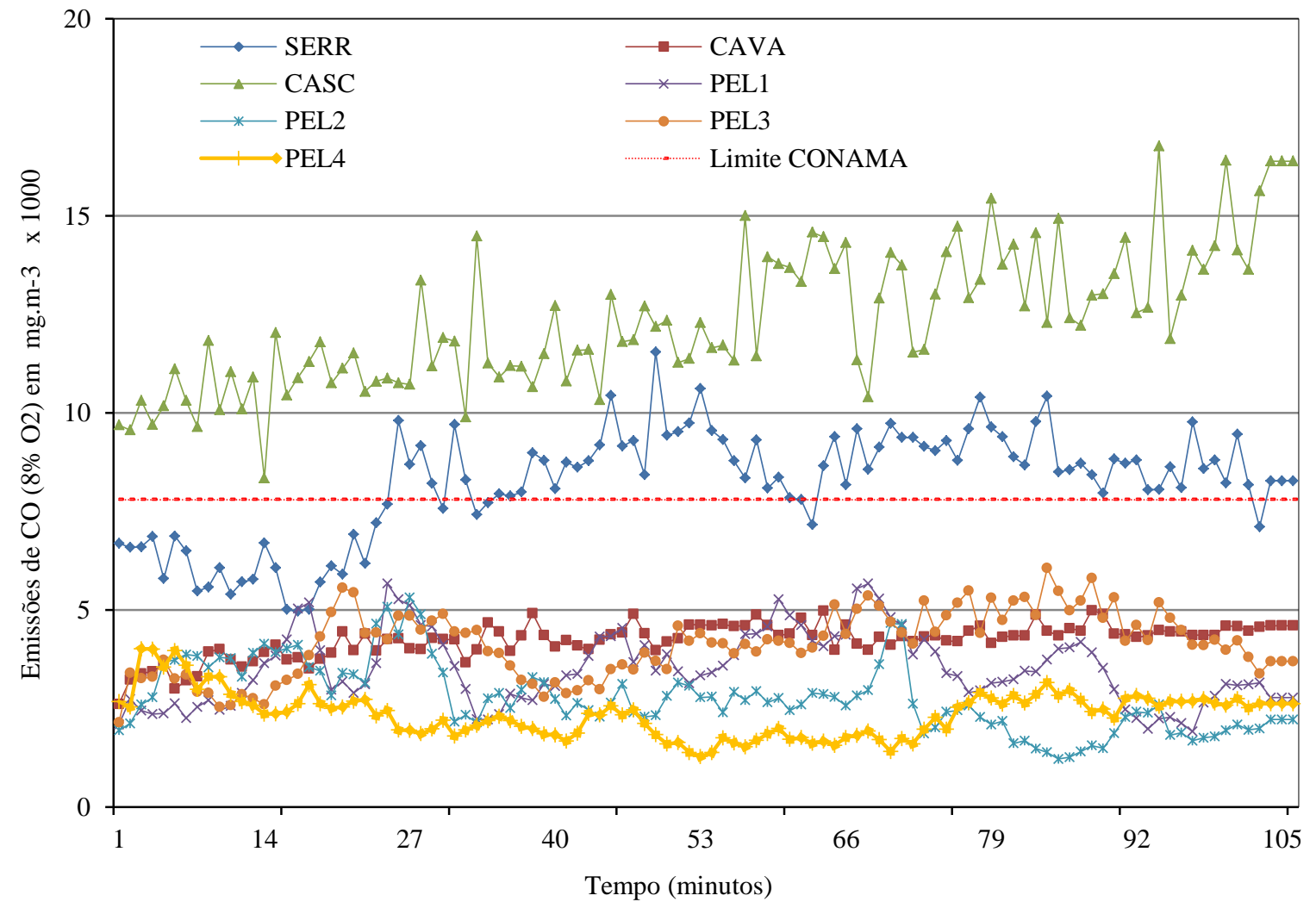

Figura 3. Emissões de monóxido de carbono durante combustão das biomassas florestais.

Figure 3. Carbon monoxide emissions during combustion of forest biomass.

As emissões de $\mathrm{NO}_{x}$ durante os testes de combustão das biomassas florestais estão apresentados na figura 4. A linha pontilhada vermelha, de $650 \mathrm{mg} \cdot \mathrm{m}^{-3}$, representa o limite máximo de emissões desses gases de acordo com a Resolução no 436 do CONAMA. 


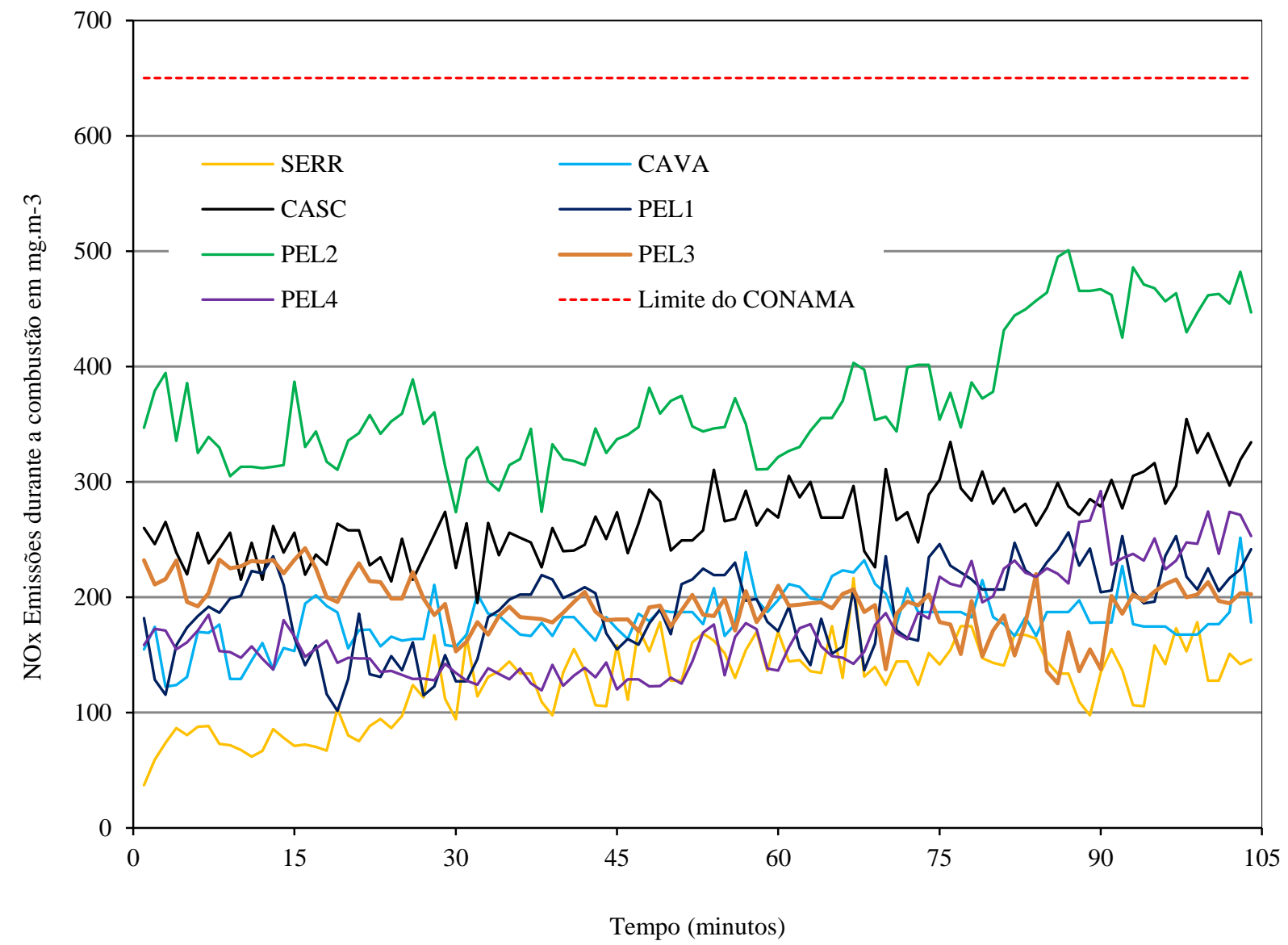

Figura 4. Emissões de óxidos de nitrogênio durante a combustão das biomassas florestais.

Figure 4. Nitrogen oxides emissions during the combustion of forest biomass.

Os resultados médios da composição química das cinzas residuais são apresentados na tabela 4.

Tabela 4. Composição química das cinzas residuais do processo de combustão das biomassas ( $\mathrm{g} \cdot \mathrm{kg}^{-1}$ cinzas).

Table 4. Chemical composition of the residual ash from the combustion process of biomass (g.kg- $\mathrm{ash})$.

\begin{tabular}{cccccccccccc}
\hline Biomassa & $\mathbf{M n O}$ & $\mathbf{F e}_{\mathbf{2}} \mathbf{O}_{\mathbf{3}}$ & $\mathbf{S i O}_{\mathbf{2}}$ & $\mathbf{C a O}$ & $\mathbf{M g O}$ & $\mathbf{A l}_{\mathbf{2}} \mathbf{O}_{\mathbf{3}}$ & $\mathbf{K}_{\mathbf{2}} \mathbf{O}$ & $\mathbf{N a}_{\mathbf{2}} \mathbf{O}$ & $\mathbf{S O}_{\mathbf{3}}$ & $\mathbf{P}_{\mathbf{2}} \mathbf{O}_{\mathbf{5}}$ & $\mathbf{T i O}_{\mathbf{2}}$ \\
\hline PEL1 & 26,1 & 43,5 & 305,0 & 228,0 & 72,8 & 71,9 & 153,0 & 5,9 & 1,9 & 51,8 & 9,0 \\
PEL2 & 17,7 & 59,7 & 441,0 & 163,0 & 41,2 & 116,0 & 80,1 & 13,5 & 0,0 & 19,5 & 12,5 \\
PEL3 & 24,9 & 48,5 & 339,0 & 224,0 & 67,1 & 76,7 & 131,0 & 10,8 & 3,2 & 34,2 & 10,1 \\
PEL4 & 3,8 & 52,3 & 505,0 & 88,5 & 16,8 & 224,0 & 31,2 & 4,4 & 0,4 & 8,3 & 17,2 \\
CASC & 1,5 & 29,0 & 763,0 & 24,2 & 6,5 & 123,0 & 13,4 & 0,0 & 0,5 & 2,9 & 10,5 \\
CAVA & 14,0 & 46,9 & 456,0 & 156,0 & 65,9 & 99,4 & 77,6 & 4,7 & 0,0 & 22,3 & 21,0 \\
SERR & 4,8 & 47,8 & 660,0 & 124,0 & 18,3 & 52,9 & 30,7 & 5,8 & 0,0 & 5,6 & 17,5 \\
\hline
\end{tabular}

\section{DISCUSSÃO}

Observando a tabela 2, nota-se a baixa densidade a granel da CASC, CAVA e SERR, juntamente com a heterogeneidade de formatos e dimensões desses materiais criam desafios logísticos para o transporte, armazenamento, movimentação, mas sobretudo para a tecnologia de combustão. Liu et al. (2010) destacam que os pellets, por terem formatos uniformes, baixa umidade e elevado poder calorífico superior, podem ter alimentação automatizada com facilidade. Por isso, são mais estáveis na queima e proporcionam combustão com baixas emissões gasosas.

Observa-se ainda, maior quantidade de cinzas residuais na casca de pinus, que pode gerar excesso de resíduos no final da combustão, aumentando a necessidade de manutenção do sistema queimador. Esse material 
apresentou menor índice de materiais voláteis e o maior índice de carbono fixo, que implica em maior tempo de residência deste biocombustível no queimador (PROTÁSIO et al., 2012; SPANHOL et al., 2015). Além disso, a casca de pinus, em comparação com as outras biomassas, apresentou-se como o material mais heterogêneo principalmente por conter elevados teores de cinzas (3,82\%), extrativos (20,73\%) e lignina $(39,62 \%)$. Para essas variáveis, López-González et al. (2013) encontraram na casca de pinus 2,7; 19,0 e 31,0\%, dessas substâncias, respectivamente, que são valores inferiores aos resultados desse estudo. Essas diferenças são naturais e podem ser explicadas pela heterogeneidade dos materiais e condições edafoclimáticas.

As cinzas são formadas por elementos inorgânicos da biomassa florestal e compõem a parte não combustível desses materiais. Assim, de acordo com Feng et al. (2013), altos teores de cinzas tendem a baixar o poder calorífico superior das biomassas. Eles relatam valores de materiais voláteis e carbono fixo semelhantes aos desse trabalho, mas os maiores teores de carbono fixo não elevou o PCS, como ocorreu nos seus estudos. De acordo com os relatos de Filbakk et al. (2011), a casca de pinus contém mais nitrogênio e enxofre do que a madeira e isto está associado com a elevada emissão de $\mathrm{NO}_{\mathrm{x}}$ e $\mathrm{SO}_{\mathrm{x}}$ durante a combustão. No entanto, nesse estudo, emissões de óxidos de enxofre não foram detectados no analisador de gás.

Como se observa na comparação da tabela 2, a casca de pinus (em geral) possui menor teor de holocelulose, maior teor de lignina e extrativos do que as outras biomassas florestais. Amaral et al. (2014) relatam que o maior teor de lignina da biomassa florestal, e consequentemente maior teor de carbono elementar, proporcionará maiores emissões de $\mathrm{CO}$ na combustão. Isso se comprovou neste estudo, com emissões médias entre 2.459-9.425 mg. $\mathrm{m}^{-3}$, enquanto a casca obteve $14.170 \mathrm{mg} . \mathrm{m}^{-3}$. A casca possui um conteúdo mineral, aproximadamente, cinco vezes maior do que a madeira (FILBAKK et al., 2011). Esses autores destacam que esses elementos inorgânicos contribuem para a sinterização das cinzas durante a combustão. Consequentemente, alto teores de cinzas originam baixa eficiência durante a queima e exigem mais manutenção e limpeza da câmara de combustão.

Analisando as substâncias encontradas nas cinzas da combustão dos materiais, verificou-se a predominância do elemento silício $(30,5 \%$ a $76,3 \%)$, na forma de sílica $\left(\mathrm{SiO}_{2}\right)$, em todas as amostras analisadas, com os maiores teores para a casca de pinus. Já o elemento cálcio, na forma de óxido de cálcio $(\mathrm{CaO})$, foi o metal alcalino predominante nos pellets PEL1 e PEL3, com 228 e 224 g.kg ${ }^{-1}$ de cinzas, respectivamente.

O nível de sílica $\left(\mathrm{SiO}_{2}\right)$ na casca de pinus e na serragem é mais que o dobro dos níveis observados nos pellets PEL1. Essa predominância ocorre devido a maior presença de elementos minerais (inorgânicos) nessa biomassa florestal do que nas outras, originando também maiores teores de cinzas que podem ser verificados na tabela 2. Destaca-se ainda que a sílica é o principal componente da areia e isso sugere que os maiores teores desse composto químico, apresentados pela casca e serragem, podem ter origem na contaminação dos materiais no transporte das biomassas do campo para a indústria (GARCIA et al., 2016a).

Sabe-se que a composição química das cinzas residuais está associada aos elementos minerais presentes na biomassa. Assim, os traços mais significativos desses elementos inorgânicos, nas cinzas residuais, foram os óxidos de silício $\left(\mathrm{SiO}_{2}\right)$, cálcio $(\mathrm{CaO})$, alumínio $\left(\mathrm{Al}_{2} \mathrm{O}_{3}\right)$, potássio $\left(\mathrm{K}_{2} \mathrm{O}\right)$, magnésio $(\mathrm{MgO})$, manganês $\mathrm{II}(\mathrm{MnO})$ e fósforo $\mathrm{V}\left(\mathrm{P}_{2} \mathrm{O}_{5}\right)$, como pode ser observado na tabela 4.Os estudos de Ferreira et al. (2014), para diversos tipos de biomassas, revelam valores de $\mathrm{SiO}_{2}$ entre $370-928$ g. $\mathrm{kg}^{-1}$, que são convergentes com os resultados desta pesquisa. Esses autores relatam ainda que a sílica, por ser um agente abrasivo, pode causar corrosão nos equipamentos queimadores e os óxidos de $\mathrm{Na}_{2} \mathrm{O}$ e $\mathrm{K}_{2} \mathrm{O}$ também têm essa característica.

Os pellets PEL1 tiveram a maior concentração de $\mathrm{K}_{2} \mathrm{O}$ com 153,0 g. $\mathrm{kg}^{-1}$ e os pellets PEL2, tiveram a maior concentração de $\mathrm{Na}_{2} \mathrm{O}$, com $13,5 \mathrm{~g} \cdot \mathrm{kg}^{-1}$. Outros óxidos metálicos foram detectados na composição das cinzas residuais tais como os óxidos de chumbo, cromo, zircônio e zinco. A presença de substâncias não metálicas também foi encontrada, como o fósforo e o enxofre, detectados na forma de pentóxido de fósforo $\mathrm{V}$ $\left(\mathrm{P}_{2} \mathrm{O}_{5}\right)$ e trióxido de enxofre $\left(\mathrm{SO}_{3}\right)$, respectivamente. Esses óxidos não metálicos podem causar uma redução no valor $\mathrm{pH}$, uma vez que, em contato com a água, formam substâncias ácidas.

Como observado na tabela 4 , traços do elemento enxofre foram encontrados nas cinzas dos pellets PEL1, PEL3, PEL4 e na casca de pinus (CASC), porém, eles podem estar relacionados à contaminação das cinzas no processo de combustão. As cinzas residuais apresentaram também traços de chumbo, crômio, níquel, zinco e zircônio, que provavelmente estão relacionados aos tipos de solos de onde as biomassas florestais cresceram (CARDOZO et al., 2014).

Na tabela 3, os resultados médios de concentração de CO obtidos, quando comparados ao limite de $7.800 \mathrm{mg} \cdot \mathrm{m}^{-3}$, recomendados pelo CONAMA, mostram que o processo de combustão em queimadores de biomassa alimentados por serragem de eucalipto (SERR) e casca de pinus (CASC), emitem além dos limites normativos (Figura 3). Para as emissões decorrentes da casca de pinus já se esperava elevados valores, uma vez que esta biomassa possui maior teor de lignina (AMARAL et al., 2014). Porém, as emissões de CO acima do limite, da serragem de eucalipto, pode ter surgido da contaminação com partículas de poeira no transporte e também pelo maior teor de umidade dessa biomassa $(14,25 \%)$, que provoca baixa eficiência na combustão

FLORESTA, Curitiba, PR, v. 47, n. 3, p. 297 - 306, jul. / set. 2017.

Garcia, D. P. et al.

ISSN eletrônico 1982-4688

DOI: $10.5380 /$ rf.v47i1.50952 
(GARCIA et al., 2016b). E, por fim, todas as amostras de pellets de madeira estão em conformidade com os limites de CO estipulados na Resolução no 436 do CONAMA (BRASIL, 2011).

Ressalta-se que os valores de CO entre 2.459-14.170 mg.m ${ }^{-3}$, encontrados nesse estudo (Tabela 3), são superiores aos resultados relatados por outros pesquisadores (CARDOZO et al., 2014; ROY et al., 2013) porque trata-se de equipamentos com potência e eficiência diferentes. Além disso, a emissão de CO é muito sensível às variáveis do processo de queima como a granulometria da biomassa, densidade a granel, teor de umidade, entrada de ar primária e secundária e atmosfera de queima do forno. Ressalta-se que altas emissões de CO da casca de pinus e da serragem de eucalipto, podem indicar combustão incompleta, possivelmente porque o forno não está otimizado para essas biomassas florestais (FILBAKK et al., 2011).

Já para as emissões de óxidos de nitrogênio, nenhuma das amostras de biomassa florestal ultrapassou os valores máximos estipulados pela resolução normativa do CONAMA, como pode ser observado na figura 3 . Todas as amostras analisadas tiveram baixos teores de óxidos de nitrogênio, como já se previa pois o próprio Conselho Nacional de Meio Ambiente não estabelece padrão de emissão de $\mathrm{NO}_{\mathrm{x}}$ para queimadores com potência nominal menor que $30 \mathrm{MW}$, como é o caso do equipamento utilizado nesse estudo (0,08 MW), mostrado na figura 2. As elevadas emissões de $\mathrm{NO}_{\mathrm{x}}$ da casca de pinus, quando comparadas às outras biomassas (Figura 4), está associada ao maior teor de nitrogênio dessa biomassa florestal, como relataram Filbakk et al. (2011), ainda assim, não oferecem riscos a saúde, de acordo com os referenciais do CONAMA (BRASIL, 2011).

Os valores para as emissões de óxidos de nitrogênio desse estudo são superiores aos relatados por outros autores (FILBAKK et al., 2011; ROY et al., 2013; CARDOZO et al., 2014). Entretanto, essas divergências se devem as diferenças na potência do equipamento queimador e eficiência da combustão. No entanto, para os critérios normativos vigentes, as emissões de $\mathrm{NO}_{\mathrm{x}}$ das biomassas florestais atendem integralmente a Resolução no 436 (BRASIL, 2011), que estabelece limite máximo de 650 mg. $\mathrm{m}^{-3}$.

Nenhuma emissão gasosa de óxido de enxofre $\left(\mathrm{SO}_{\mathrm{x}}\right)$ foi detectada pelo equipamento eletroquímico nas biomassas. Estudos de Garcia-Maraver et al. (2014), analisaram o percentual de enxofre em diversos resíduos agroflorestais como a casca de arroz, o sorgo e resíduos da madeira de pinus e encontraram valores referenciais entre 0,1-0,6\% desse elemento. Já os estudos de Pirraglia et al. (2012), analisando seis espécies de eucaliptos, concluíram que a composição de enxofre nessa biomassa florestal foi insignificante, ou seja, tipicamente inferior a 0,1\%. No entanto, alguns autores (CARDOZO et al., 2014; ROY et al., 2013) relatam emissões de óxidos de enxofre entre $0,01-0,03 \% \mathrm{mg} \cdot \mathrm{m}^{-3}$, para diversos tipos de biomassas florestais. Possivelmente por essas baixas emissões características de óxidos de enxofre na combustão de derivados da biomassa florestal, a Resolução $\mathrm{n}^{\mathbf{0}}$ 436 (BRASIL, 2011), não prevê nenhum parâmetro limitante para esses poluentes.

A composição dos gases da combustão incompleta dos biocombustíveis refletem a composição química dessas biomassas, mas também dependem das condições da combustão. Alterações na temperatura da queima ou entradas de ar atmosférico, por exemplo, podem diminuir as emissões poluentes e favorecer o atendimento dos requisitos da legislação do CONAMA. Além disso, a casca de pinus e a serragem de eucalipto, que tiveram os maiores índices de emissões de CO, apesar de tudo, são combustíveis neutros em carbono e a quantidade de CO ou $\mathrm{CO}_{2}$, que foi liberada na queima, já foi compensada no período de crescimento da árvore, como apontaram Garcia et al. (2016a).

A casca de pinus foi a biomassa florestal com a maior quantidade de emissões poluentes na combustão. Para sua correta utilização, faz-se necessário o emprego de equipamento industrial para captura dos gases poluentes da combustão, como por exemplo, um precipitador eletrostático.

\section{CONCLUSÕES}

As análises dos pellets de madeira e outras biomassas florestais permitem concluir que:

- Os pellets de madeira e os cavacos de pinus têm emissões de monóxido de carbono abaixo do limite de $7.800 \mathrm{mg} \cdot \mathrm{m}^{-3}$ estabelecido pela Resolução do CONAMA;

- As emissões gasosas de óxidos de nitrogênio dos pellets, serragem de eucalipto, cavaco e casca de pinus encontram-se abaixo dos $650 \mathrm{mg} \cdot \mathrm{m}^{-3}$ fixado na Resolução do CONAMA;

- A casca de pinus ultrapassa o limite de emissões de monóxido de carbono estabelecidos na Resolução do CONAMA e seu aproveitamento está condicionado ao uso de equipamento de captura de gases poluentes da combustão;

- Não constatou-se emissões gasosas de óxidos de enxofre na combustão dos pellets de madeira nem nas outras biomassas florestais. 


\section{REFERÊNCIAS}

ADAMS, P. W. R.; LINDEGAARD, K. A critical appraisal of the effectiveness of UK perennial energy crops policy since 1990. Renewable and Sustainable Energy Reviews, Amsterdam, v. 55, p. 188-202, 2016.

AMARAL, S. S.; JUNIOR, J. A. C.; COSTA, M. A. M.; NETO, T. G. S.; DELlANI, R.; LEITE, L. H. S. Comparative study for hardwood and softwood forest biomass: Chemical characterization, combustion phases and gas and particulate matter emissions. Bioresource Technology, Amsterdam, v. 164, p. 55-63, 2014.

ASSOCIAÇÃO BRASILEIRA DE NORMAS TÉCNICAS (ABNT). NBR 8633: Carvão Vegetal (Adaptada para pellets) - Determinação do poder calorífico superior. Rio de Janeiro, 1984.

ASSOCIAÇÃO BRASILEIRA DE NORMAS TÉCNICAS (ABNT). NBR 8112: Carvão Vegetal (Adaptada para pellets) - Análise Imediata. Rio de Janeiro, 1986.

ASSOCIAÇÃO BRASILEIRA DE NORMAS TÉCNICAS (ABNT). NBR 14929: Madeira - Determinação do teor de umidade de cavacos. Rio de Janeiro, 2003.

BISWAS, A. K.; YANG, W.; BLASIAK, W. Steam pretreatment of Salix to upgrade biomass fuel for wood pellet production. Fuel Processing Technology, Amsterdam, v. 92, n. 9, p. 1711-1717, 2011.

BRASIL. CONSELHO NACIONAL DO MEIO AMBIENTE (CONAMA). Resolução no 436, 13 de maio de 2011. Brasília, 2011.

CARDOZO, E.; ERLICHA, C.; ALEJOB, L.; FRANSSONA, T. H. Combustion of agricultural residues: An experimental study for small-scale applications. Fuel, Amsterdam, v. 115, p. 778-787, 2014.

CARROLL, J.; FINNAN, J. Emissions and efficiencies from the combustion of agricultural feedstock pellets using a small scale grate boiler. Biosystems Engineering, Amsterdam, v. 115, n. 1, p. 50-55, 2013.

CORNWALL, W. The burning question. Science, New York, v. 355, n. 6320, p. 18-21, 2017.

COMMITTEE EUROPEAN STANDARDIZATION (CEN). CEN/TS 15103 - Methods for determination of bulk density. London, 2005.

FENG, S.; CHENG, S.; ZHONGSHUN, Y.; MATHEW, L.; XU, C. C. Valorization of bark for chemicals and materials: A review. Renewable and Sustainable Energy Reviews, Amsterdam, v. 26, p. 560-578, 2013.

FERREIRA, P. T.; FERREIRA, M. E.; TEIXEIRA, J. C. Analysis of Industrial Waste in Wood Pellets and Cocombustion Products. Waste and Biomass Valorization, London, v. 5, n. 4, p. 637-650, 2014.

FILBAKK, T.; JIRJIS, R.; NURMI, J.; HØIBØ, O. The effect of bark content on quality parameters of Scots pine (Pinus sylvestris L.) pellets. Biomass and Bioenergy, Amsterdam, v. 35, n. 8, p. 3342-3349, 2011.

GARCIA, D. P.; CARASCHI, J. C.; VENTORIM, G. Decomposição térmica de pellets de madeira por TGA. Holos, Natal, v. 1, n. 32, p. 1-13, 2016a.

GARCIA, D. P.; CARASCHI, J. C.; VENTORIM, G.; VIEIRA, F. H. A. Trends and challenges of origin brazilian agroforestry pellets industry. Cerne, Lavras, v. 1, n. 1, p. 1-18, 2016 b.

GARCIA-MARAVER, A.; ZAMORANO, M.; FERNANDES, U.; RABAÇAL, M.; COSTA, M. Relationship between fuel quality and gaseous and particulate matter emissions in a domestic pellet-fired boiler. Fuel, Amsterdam, v. 119, p. 141-152, 2014.

IPCC. Climate Change 2014: Migation of Climate Change. Summary for Policymakers of the Working Group III (WGIII) contribution to the Fifth Assessment Report (AR5). WMO: UNEP - United Nations Environment Programme. Berlin, 2014. 45p.

JOELSSON, J. M.; GUSTAVSSON, L. Reduction of $\mathrm{CO}_{2}$ emission and oil dependency with biomass-based polygeneration. Biomass and Bioenergy, Amsterdam, v. 34, n. 7, p. 967-984, 2010.

LIU, H.; QIU, G.; SHAO, Y.; RIFFAT, S. B. Experimental investigation on flue gas emissions of a domestic biomass boiler under normal and idle combustion conditions. International Journal of Low-Carbon Technologies, Oxford, v. 5, n. 2, p. 88-95, 2010.

LÓPEZ-GONZÁLEZ, D.; FERNANDEZ-LOPEZ, M.; VALVERDE, J. L.; SANCHEZ-SILVA, L. Thermogravimetric-mass spectrometric analysis on combustion of lignocellulosic biomass. Bioresource 
Technology, Amsterdam, v. 143, p. 562-574, 2013.

PROTÁSIO, T. P.; BUfAliNO, L.; MENDES, R. F.; RIBEIRO, M. X.; TRUGILHO, P. F.; LEITE, E. R. S. Torrefação e carbonização de briquetes de resíduos do processamento dos grãos de café. Revista Brasileira de Engenharia Agrícola e Ambiental, Campina Grande, v. 16, n. 11, p. 1252-1258, 2012.

ROY, M. M.; DUTTA, A.; CORSCADDEN, K. An experimental study of combustion and emissions of biomass pellets in a prototype pellet furnace. Applied Energy, Amsterdam, v. 108, p. 298-307, 2013.

SPANHOL, A.; NONES, D. L.; KUMABE, F. J. B.; BRAND, M. A. Qualidade dos pellets de biomassa florestal produzidos em Santa Catarina para a geração de energia. Floresta, Curitiba, v. 45, n. 4, p. 833-844, 2015.

TECHNICAL ASSOCIATION OF THE PULP AND PAPER INDUSTRY (TAPPI). Ash in wood and pulp. T 211 om-93 - Standard Method. Atlanta, 2000. 